SA Johner, T Remer. DONALD Study, University of Bonn, Research Institute of Child Nutrition, Dortmund, Germany

Purpose Even mild iodine deficiency may negatively affect cognitive performance, especially at a young age. Our aim was to investigate iodine status in very young children and to assess the importance of iodized salt in processed foods as an example for a country with voluntary salt iodization.

Methods 24-h urinary iodine excretion (UIE) as a marker of iodine intake was measured in 378 repeatedly collected 24 -h urine samples (2003-2010) of $2213-<6$ year old participants of the DONALD Study. Parallel 3-d weighed dietary records and measurements of urinary sodium excretion provided data on the daily consumption of the most important iodine providers in the children's diet (iodized salt, milk, fish, meat and eggs). Time trends of UIE (2003-2010) and contributions of the different food groups were analysed by using linear mixed-effects regression models.

Results Median UIE of $71 \mu \mathrm{g} / \mathrm{d}$ in boys and $65 \mu \mathrm{g} / \mathrm{d}$ in girls, corresponding to an iodine intake of 82 and $75 \mu \mathrm{g} / \mathrm{d}$, respectively (assumption: $15 \%$ non renal iodine losses) was below the WHO intake recommendations of $90 \mu \mathrm{g} / \mathrm{d}$. Milk, salt and egg intake were significant predictors of UIE; milk and salt together accounted for $>80 \%$ of iodine supply. Between 2003 and 2010, UIE decreased significantly by approximately $1 \mu \mathrm{g} /$ year. The contribution of salt intake to UIE decreased from 03-06 to 07-10.

Conclusion In countries where salt is a major iodine provider, already modest decreases in the iodized proportion of salt used in processed foods may relevantly impair iodine status even in preschool children.

\section{VITAMIN B12 LEVELS OF 0-24 YEARS-0LD PEOPLE IN KONYA, TURKEY}

doi:10.1136/archdischild-2012-302724.1047

${ }^{1} \mathrm{~F}$ Akin, ${ }^{2 \mathrm{H}}$ Yavuz, ${ }^{3} \mathrm{~S}$ Bodur, ${ }^{4} \mathrm{~A}$ Kiyici. ${ }^{1}$ Konya Training and Research Hospital; ${ }^{2}$ Pediatrics; ${ }^{3}$ Public Health, Konya University, Meram Medical Faculty; "Biochemistry, Selcuk University, Selcuklu Medical Faculty, Konya, Turkey

Background It was reported that levels of vitamin B12 show racial differences. Therefore we wanted to determine normal serum levels of vitamin B12 in Konya region, Turkey.

Methods Totally 1109 samples of which 54 were cord bloods and the rest were 1055 healthy $0-24$ years-old subjects who admitted to primary health centers. Vitamin B12 measurement was done at the biochemistry laboratory of Selcuk University Meram Medical Faculty with the original Beckman kits (Beckman Coulter, CaliforniaUSA) by chemiluminesans method.

Results The reference levels obtained for vitamin B12 at $\mathrm{P}_{2.5}-\mathrm{P}_{97.5}$ range were; $127-606 \mathrm{pg} / \mathrm{ml}$ for girls and $127-576 \mathrm{pg} / \mathrm{ml}$ for boys. Reference level for the total study group was $127-590 \mathrm{pg} / \mathrm{ml}$.

Conclusion The values reported in other studies are higher than our results. Vitamin B12 levels vary among countries. Using reference ranges of other populations may lead to inaccurate results. Therefore normal levels which will be valid for that population should be obtained.

\section{INFANTICIDE, 'AFTER-BIRTH ABORTION' AND RECENT PHILOSOPHICAL CONTROVERSIES CONCERNING THE VALUE OF NEWBORN LIFE}

doi:10.1136/archdischild-2012-302724.1048

J Wyatt. Institute for Womens Health, UCL Institute of Child Health and Great Ormond Street Hospital for Children, London, UK

The Journal of Medical Ethics recently published an article by philosophers Guibilini and Minerva (1) arguing that the intentional killing of newborn infants was justified if the continued existence of the child represented 'an unbearable burden for the psychological health of the woman or for her already existing children', as well as if there were excessive economic burdens or disability. They argued that both fetuses and newborns do not have the same moral status as actual persons, since they lack self-awareness. Hence the destruction of a newborn life is morally justified if it is in the best interests of existing people. Although the position of Guibilini and Minerva is supported by several other prominent philosophers, including Michael Tooley and Peter Singer, I will argue that it is fatally flawed.

a) It is incoherent to argue that conscious self-awareness is necessary criterion for life to have intrinsic value,

b) The argument strikes at the heart of the central belief enshrined in the Universal Declaration of Human Rights, that all human beings possess inherent moral worth solely in virtue of their membership of the human species, and irrespective of their functional abilities,

c) Since self-awareness as an agent probably does not start to appear before 18 months of age, and may not be secure until the fourth year of life, the argument imperils not just newborns but a large proportion of the paediatric population!

Reference Giubilini, A, Minerva F, J Med Ethics epub 3 Feb 2012.

\section{BURDEN OF CHRONIC EXPOSURE TO DIFFICULT ETHICAL DECISIONS ON CARE CAREGIVERS IN SWISS NICUS}

doi:10.1136/archdischild-2012-302724.1049

N Hauser, HU Bucher, JC Fauchere. Division of Neonatology, Univ. Hospital Zurich, Zurich, Switzerland

Aim This study explored the degree of burden of chronic exposure to difficult ethical decisions on health care providers (HCP) in Swiss level III NICUs.

Methods 224 questionnaires were sent to neonatologists and nurses of all level III NICUs. Demographical information, attitudes and behaviours towards ethical decisions, and the impact of those decisions on HCP's health and private life were collected.

Results 52 neonatal physicians and 60 nurses $(27$ men, 85 women, overall response rate 50\%) took part in this survey. Altogether, $78 \%$ stated that the ethical dilemmas/decision-making represent a burden to them. $87 \%$ experience this burden as momentary. In nearly $40 \%$, this burden affects private life; in another $48 \%$ it occasionally impact on private life. $25 \%$ of physicians and $10 \%$ nurses suffer from exhaustion. Most of the respondents find relief from stress through their hobbies (70\%) and discussions with family members and friends (74\%). The most used coping strategies are debriefings after ethical discussions, team discussions and support from hospital pastoral care. Professional moderation of debriefings was only rarely available (10\%).

Conclusion Chronic exposure to stressful situations represents a burden for the majority of HCP working in NICU environment. Exhaustion is far more frequent than physical and psychosomatic symptoms. Hobbies and social contacts are important coping strategies. Given the potential of chronic burden to not only affect health of caregiver but also to shape the attitudes of caregivers in daily neonatal intensive care medicine, the importance of team debriefings and support under professional guidance cannot be stressed enough.

\section{ETHICAL DILEMMA IN NEONATOLOGY}

doi:10.1136/archdischild-2012-302724.1050

SA Ahmed, A Arasu. Neonatology, Luton \& Dunstable Hospital NHS Foundation Trust, Luton, UK

Aim To ascertain parents' attitude, knowledge and awareness of the type of Surfactant used in the Neonatal unit to treat Respiratory Distress Syndrome and their religious perspective. 